TITLE:

\title{
Larger chimpanzee-dispersed seeds are elongated at Mahale, Tanzania: Possible consequence of plant-disperser interaction?
}

\author{
$\operatorname{AUTHOR}(\mathrm{S})$ :
}

Nakamura, Michio; Itoh, Noriko

\section{CITATION:}

Nakamura, Michio ...[et al]. Larger chimpanzee-dispersed seeds are elongated at Mahale, Tanzania: Possible consequence of plant-disperser interaction?. Journal of Tropical Ecology 2015, 31(2): 183-186

ISSUE DATE:

2015-03-05

URL:

http://hdl.handle.net/2433/218344

\section{RIGHT:}

This is the author's version of the following article. Nakamura M, Itoh N 2015. Larger chimpanzee-dispersed seeds are elongated at Mahale, Tanzania: possible consequence of plant-disperser interaction? Journal of Tropical Ecology 31:183-186. https://doi.org/10.1017/S0266467414000765; @ Cambridge University Press 2015; この論文は出版社版であ りません。引用の際には出版社版をご確認じ利用ください。; This is not the published version. Please cite only the published version. 
NOTICE: This is the author's version of the following article.

Nakamura M, Itoh N 2015. Larger chimpanzee-dispersed seeds are elongated at Mahale, Tanzania: possible consequence of plant-disperser interaction? Journal of Tropical Ecology 31:183-186. https://doi.org/10.1017/S0266467414000765

(C) Cambridge University Press 2015

\title{
Larger chimpanzee-dispersed seeds are elongated at Mahale, Tanzania: possible consequence of plant-disperser interaction?
}

\author{
Michio Nakamura ${ }^{1}$ and Noriko Itoh
}

Wildlife Research Center, Kyoto University, 2-24 Tanaka-Sekiden-Cho, Sakyo, Kyoto, 606-8203, Japan

${ }^{1}$ Corresponding author. Email: nakamura@wrc.kyoto-u.ac.jp

\begin{abstract}
Apes are important long-distance dispersers of large seeds in African tropical forests. Seed size and shape are likely to affect the ease of swallowing for an animal species. If an endozoochorous seed is larger than the digestive tract of an animal, the seed cannot be swallowed, and a round seed is more difficult to swallow than an elongated seed of the same length. In order to test if such a correlation exists between the seed size and its shape, we investigated the length and width of chimpanzee-dispersed seeds at the Mahale Mountains National Park, Tanzania. Among the 14 species of seeds, longer seeds had significantly narrower relative widths, and thus, they were more ovoid. Since the chimpanzee is the largest arboreal frugivore at Mahale, their food selection might have influenced the shape of larger seeds. The chimpanzee's selective consumption of such fruits with longer, elongated seeds may have facilitated the selective dispersal of such plant species in that area.
\end{abstract}

Keywords: Endozoochory, Mahale Mountains National Park, Pan troglodytes, Seed dispersal, Seed volume

Frugivorous primates are important seed dispersers (Chapman 1995) in neotropical and palaeotropical forests. In African forests, the most abundant cercopithecoid monkeys swallow smaller seeds up to $0.4 \mathrm{~cm}$ in size (Lambert 1999), and often spit out larger seeds. On the other hand, great apes, which have the largest bodies among African primates, swallow large seeds and defecate them intact in their faeces (Gorilla gorilla Savage 1847: Tutin et al. 1991; Pan troglodytes Blumenbach 1775: Wrangham et al. 1994; Pan paniscus Schwarz 1929: Idani 1986), thus acting as important long-distance dispersers. For example, in Dja Forest, Cameroon, about half of the seeds dispersed via primate faeces were done so by apes, despite their low densities (Poulsen et al. 2001). It is also known that seeds from chimpanzee faeces have higher germination potential than those that have not passed through the gut (Takasaki 1983, Wrangham et al. 1994).

Size may be a limiting factor that determines whether a seed is swallowed by an animal. If it is larger than the animal's oesophagus, the animal cannot physically swallow it. The allometry of a seed is also relevant, because even with identical lengths, a rounder seed is more difficult to swallow than an elongated one. According to 
Chapman (1995), 'it seems reasonable to speculate that selection may favour seeds that are ovate and elongate, like many pills'. However, there have been only a few empirical studies on seed size and shape in relation to endozoochory (Forget et al. 2007, Lord 2004). The width of a seed, which is orthogonal to the digestive tract, strongly restricts the swallowing action of an animal. However, most of the studies on chimpanzee seed dispersal presented only the length of the seeds and provided no information on their width (Gross-Camp et al. 2009, Lambert \& Garber 1998, Poulsen et al. 2001, Wrangham et al. 1994; but Lambert 1999 provided some data).

Thus, in this study, we present data on the length and width of seeds that are either dispersed or not dispersed by chimpanzees at the Mahale Mountains National Park, Tanzania (see Nakamura \& Nishida 2012 for the study site). Dispersed seeds (243 seeds from 14 plant species) are those known to be swallowed together with fruit pulp by the chimpanzees and are defecated intact in their faeces. The majority of them were collected from chimpanzee faeces, and those that were difficult to identify were collected directly from ripe fruits. Non-dispersed seeds (254 seeds belonging to 12 species) are those either destroyed or not utilized at all by the chimpanzees.

We measured the longest axis (length) and the orthogonal second-longest axis (width) of each seed with a calliper to the nearest $0.05 \mathrm{~mm}$. Plant species and seed length, width and ellipticity are given in Table 1 . The average ellipticity in each chimpanzee-dispersed plant species varied from more rounded Psydrax (ellipticity $=0.85)$ to more elongated Cordia (ellipticity $=0.52)$.

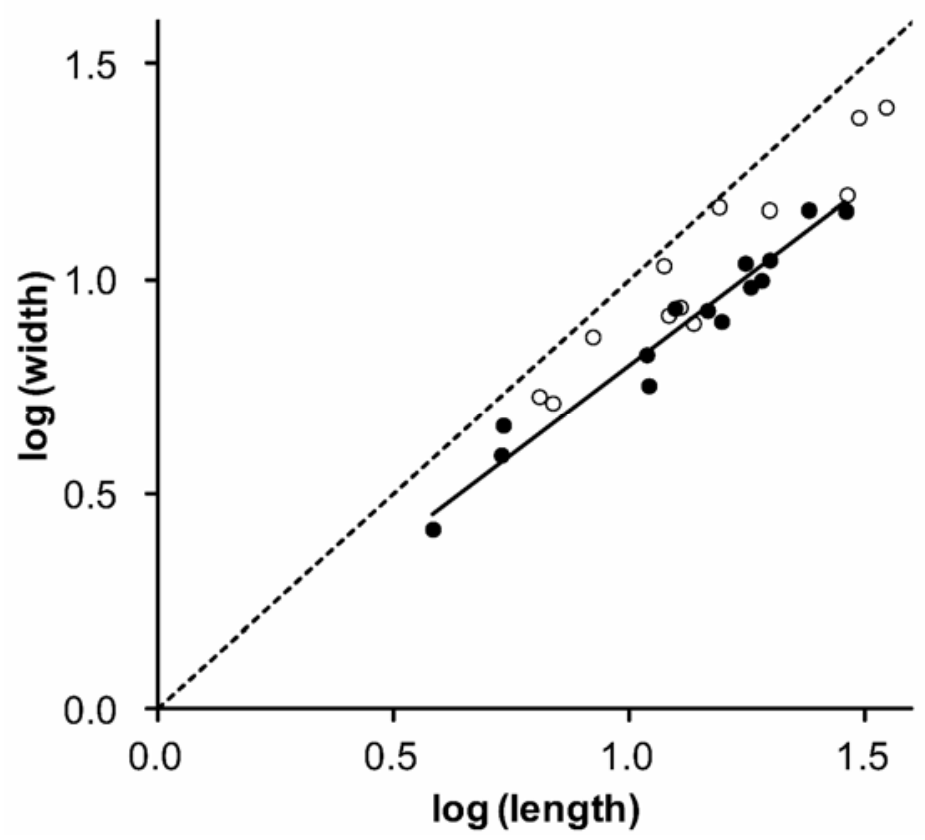

Figure 1. Standardized major-axis regression for log-transformed length vs. width of chimpanzee-dispersed seeds (black dots) and non-chimpanzee-dispersed seeds (white dots) at Mahale. Each dot represents the average size of a seed in a species. The dashed line shows a slope of 1.0, and the solid line shows a slope for the black dots. 
Table 1 Seed size and ellipticity in 14 plant species whose seeds are swallowed whole (dispersed), and 12 species whose seeds are either destroyed or not utilized (non-dispersed) by Mahale chimpanzees.

Ellipticity = width/length: when approaching 0, the shape is more elongated, and when approaching 1, the shape is more rounded.

\begin{tabular}{|c|c|c|c|c|c|}
\hline Species & Family & $\mathrm{N}$ & $\begin{array}{l}\text { Mean length } \\
(\mathrm{mm} \pm \mathrm{SD})\end{array}$ & $\begin{array}{l}\text { Mean width } \\
(\mathrm{mm} \pm \mathrm{SD})\end{array}$ & $\begin{array}{c}\text { Mean } \\
\text { ellipticity }\end{array}$ \\
\hline \multicolumn{6}{|l|}{ Chimpanzee-dispersed seeds } \\
\hline Cordia millenii Baker & Boraginaceae & 9 & $28.8 \pm 5.22$ & $14.4 \pm 0.99$ & 0.52 \\
\hline Pycnanthus angolensis (Welw.) Warb. & Myristicaceae & 24 & $24.0 \pm 2.56$ & $14.5 \pm 1.50$ & 0.61 \\
\hline Myrianthus arboreus P.Beauv. & Cecropiaceae & 22 & $19.8 \pm 1.69$ & $11.1 \pm 1.46$ & 0.56 \\
\hline Saba comorensis (Bojer ex A.DC.) Pichon & Apocynaceae & 25 & $19.1 \pm 1.81$ & $9.97 \pm 1.05$ & 0.53 \\
\hline Mimusops bagshawei S.Moore & Sapotaceae & 13 & $18.1 \pm 1.40$ & $9.62 \pm 0.94$ & 0.54 \\
\hline Synsepalum brevipes (Baker) T.D.Penn. & Sapotaceae & 6 & $17.6 \pm 3.05$ & $10.9 \pm 1.35$ & 0.63 \\
\hline Landolphia owariensis P.Beauv. & Apocynaceae & 28 & $14.6 \pm 1.92$ & $8.49 \pm 1.05$ & 0.59 \\
\hline Garcinia huillensis Welw. & Guttiferae & 19 & $12.5 \pm 1.05$ & $8.58 \pm 0.99$ & 0.69 \\
\hline Tabernaemontana pachysiphon Stapf & Apocynaceae & 9 & $11.0 \pm 1.49$ & $5.67 \pm 0.63$ & 0.52 \\
\hline Uvaria angolensis Welw. ex Oliv. & Annonaceae & 13 & $10.9 \pm 1.26$ & $6.69 \pm 1.03$ & 0.62 \\
\hline Psydrax parviflora (Afzel.) Bridson & Rubiaceae & 25 & $5.40 \pm 0.43$ & $4.58 \pm 0.40$ & 0.85 \\
\hline Psychotria peduncularis (Salisb.) Steyerm. & Rubiaceae & 22 & $5.35 \pm 0.22$ & $3.90 \pm 0.33$ & 0.73 \\
\hline Toddalia asiatica (L.) Lam. & Rutaceae & 8 & $3.83 \pm 0.23$ & $2.62 \pm 0.16$ & 0.69 \\
\hline \multicolumn{6}{|l|}{ Non-chimpanzee-dispersed seeds } \\
\hline Julbernardia seretii (De Wild.) Troupin & Leguminosae-Caesalpinioideae & 26 & $30.6 \pm 2.37$ & $23.8 \pm 2.13$ & 0.78 \\
\hline Afzelia quanzensis Welw. & Leguminosae-Caesalpinioideae & 20 & $28.9 \pm 3.35$ & $15.7 \pm 1.55$ & 0.55 \\
\hline Bauhinia petersiana Bolle & Leguminosae-Caesalpinioideae & 20 & $19.8 \pm 1.27$ & $14.5 \pm 1.75$ & 0.74 \\
\hline Monotes elegans Gilg & Dipterocarpaceae & 23 & $15.5 \pm 0.89$ & $14.8 \pm 0.92$ & 0.96 \\
\hline Margaritaria discoidea (Baill.) G.L.Webster & Euphorbiaceae & 19 & $13.7 \pm 2.63$ & $7.92 \pm 1.83$ & 0.58 \\
\hline Aporrhiza paniculata Radlk. & Sapindaceae & 19 & $12.8 \pm 1.15$ & $8.63 \pm 0.48$ & 0.68 \\
\hline Sterculia tragacantha Lindl. & Sterculiaceae & 23 & $12.1 \pm 0.89$ & $8.27 \pm 0.56$ & 0.69 \\
\hline Dracaena mannii Baker & Dracaenaceae & 18 & $11.8 \pm 2.56$ & $10.8 \pm 2.08$ & 0.92 \\
\hline Albizia glaberrima (Schum. \& Thonn.) Benth. & Leguminosae-Mimosoideae & 24 & $8.35 \pm 0.62$ & $7.36 \pm 0.69$ & 0.88 \\
\hline Abrus precatorius L. & Leguminosae-Papilionoideae & 20 & $6.87 \pm 0.28$ & $5.16 \pm 0.15$ & 0.75 \\
\hline Marantochloa leucantha (K.Schum.) Milne-Redh. & Marantaceae & 20 & $6.43 \pm 0.23$ & $5.34 \pm 0.26$ & 0.83 \\
\hline
\end{tabular}


After log-transforming the length and width values (to improve normality), we regressed seed width against seed length by standardized major-axis regressions in order to test whether larger seeds have more elongated shapes (relatively narrower widths) compared with smaller ones. When the resulting slope is less than 1.0 and the $95 \%$ confidence interval is not overlapping with 1.0, the width of larger seeds is regarded to be significantly narrower than expected from the seed length. Figure 1 (black dots) shows the log-transformed average lengths and widths of seeds from 14 chimpanzee-dispersed plant species. The resulting slope was significantly lower than 1.0 (slope $=0.83,95 \% \mathrm{CI}=0.72-0.94, \mathrm{P}=0.0080$ ). Thus, at the species level, larger seeds swallowed by the Mahale chimpanzees were more elongated. When we used all individual seeds for analysis, this trend was also observed (slope $=0.80,95 \%$ $\mathrm{CI}=0.77-0.84, \mathrm{P}<0.0001)$. On the other hand, the slope for the non-dispersed seed species did not significantly differ from 1.0 (Figure 1, white dots: slope $=0.93,95 \%$ $\mathrm{CI}=0.75-1.15, \mathrm{P}=0.48$ ). However, the slopes for dispersed and non-dispersed seeds did not significantly differ (Common Slope Test, $\mathrm{P}=0.30$ ).

Because the 14 plant species, with seeds that were dispersed by chimpanzees, belong to various taxa, the observed pattern may be generally shared among those plant species that are adapted to seed dispersal by Mahale chimpanzees. Even phylogenetically related species follow this general pattern; besides Cordia millenii (Table 1), another Cordia species found at Mahale, C. africana, is also eaten by chimpanzees. Seeds of C. africana are much smaller (approximately 70-80 mm) and visibly rounder than the larger $C$. millenii.

The regression analysis of an already published dataset for gibbons (hybrid of Hylobates agilis and $H$. muelleri) (McConkey2000) produced a similar result (slope $=0.41,95 \% \mathrm{CI}=0.21-0.80, \mathrm{P}=0.013$ ). Thus, this trend may also be observed in other apes that swallow relatively large seeds in palaeotropical forests. On the other hand, seeds typically swallowed by the long-tail macaque (Macaca fascicularis) (data shown as ' $W$ ' in Table I of Lucas \& Corlett 1998) did not show such a trend (slope $=1.24,95 \% \mathrm{CI}=0.93-1.65, \mathrm{P}=0.12$ ), probably because macaques usually swallow much smaller seeds and spit out larger ones (Lucas \& Corlett 1998).

The production of larger seeds may be beneficial for plants since they contain more nutrition for germination. However, there is also a risk that such seeds may not be swallowed by dispersers if the size is too large. At Mahale, the chimpanzee is the largest seed disperser. At the same time, we have never observed Mahale chimpanzees utilizing fruits whose seeds are too large to swallow, except for human-introduced Mangifera indica L. Without larger seed dispersers in Mahale, chimpanzees may be the limiting factor for the size and shape of seeds in this region. Through frequent dispersal by 
chimpanzees, plants that produce seeds that can be swallowed by chimpanzees may have an advantage over those that produce seeds of the same size but which are more rounded, and they may have increased long-term relative abundances. This, in turn, should facilitate frequent consumption of such fruits by chimpanzees. Such a positive loop may partly explain why large seeds that are dispersed by chimpanzees tend to have elongated shapes at Mahale.

\section{Acknowledgements}

We thank the Tanzania Commission for Science and Technology, the Tanzania National Parks, and the Tanzania Wildlife Research Institute for permission to do research in Mahale as well as MMCRP members for their cooperation in maintaining the field site.

\section{Literature Cited}

CHAPMAN, C. A. 1995. Primate seed dispersal: coevolution and conservation implications. Evolutionary Anthropology 4:74-82.

FORGET, P. M.,DENNIS, A. J.,MAZER, S. J., JANSEN, P.A., KITAMURA, S., LAMBERT, J. E. \& WESTCOTT, D. A. 2007. Seed allometry and disperser assemblages in tropical rainforests: a comparison of four floras on different continents. Pp. 5-36 in Dennis, A. J., Green, R. A., Schupp, E. W. \& Westcott, D. A. (eds.). Seed dispersal. CAB International, Wallingford.

GROSS-CAMP, N. D., MASOZERA, M. \& KAPLIN, B. A. 2009. Chimpanzee seed dispersal quantity in a tropical montane forest of Rwanda. American Journal of Primatology 71:901-911.

IDANI, G. 1986. Seed dispersal by pygmy chimpanzees (Pan paniscus): a preliminary report. Primates 27:441-447.

LAMBERT, J. E. 1999. Seed handling in chimpanzees (Pan troglodytes) and redtail monkeys (Cercopithecus ascanius): implications for understanding hominoid and cercopithecine fruit-processing strategies and seed dispersal. American Journal of Physical Anthropology 109:365-386.

LAMBERT, J. E. \& GARBER, P. A. 1998. Evolutionary and ecological implications of primate seed dispersal. American Journal of Primatology 45:9-28.

LORD, J. M. 2004. Frugivore gape size and the evolution of fruit size and shape in southern hemisphere floras. Austral Ecology 29:430-436.

LUCAS, P. W. \& CORLETT, R. T. 1998. Seed dispersal by long-tailed macaques. American Journal of Primatology 45:29-44.

MCCONKEY, K. R. 2000. Primary seed shadow generated by gibbons in the rain forest of Barito Ulu, Central Borneo. American Journal of Primatology 52:13-29. 
NAKAMURA, M. \& NISHIDA, T. 2012. Long-term field studies of chimpanzees at Mahale Mountains National Park, Tanzania. Pp. 339-356 in Kappeler, P. M. \& Watts, D. P. (eds.). Long-term studies of primates. Springer, Heidelberg.

POULSEN, J. R., CLARK, C. J. \& SMITH, T. B. 2001. Seed dispersal by a diurnal primate community in the Dja Reserve, Cameroon. Journal of Tropical Ecology 17:787-808.

TAKASAKI, H. 1983. Seed dispersal by chimpanzees: a preliminary note. African Study Monographs 3:105-108.

TUTIN, C. E. G., WILLIAMSON, E. A., ROGERS, M. E. \& FERNANDEZ, M. 1991. A case study of a plant-animal relationship: Cola lizae and lowland gorillas in the Lopé Reserve, Gabon. Journal of Tropical Ecology 7:181-199.

WRANGHAM, R.W., CHAPMAN, C. A. \& CHAPMAN, L. J. 1994. Seed dispersal by forest chimpanzees in Uganda. Journal of Tropical Ecology 10:355-368. 